\title{
NIR SPECTROSCOPY CAN EVALUATE THE CRYSTALLINITY AND THE TENSILE AND BURST STRENGTHS OF NANOCELLULOSIC FILMS
}

\author{
Lívia Cássia Viana ${ }^{1, \star}$, Graciela Ines Bolzon de Muniz ${ }^{1}$, Paulo Ricardo Gherardi Hein ${ }^{2}$, \\ Washington Luiz Esteves Magalhães ${ }^{3}$, Mayara Elita Carneiro ${ }^{1}$
}

\begin{abstract}
The near infrared (NIR) spectroscopy presents itself as an interesting non-destructive test tool as it enables a fast, simple and reliable way for characterizing large samplings of biological materials in a short period of time. This work aimed to establish multivariate models to estimate the crystallinity indices and tensile and burst strength of cellulosic and nanocellulosic films through NIR spectroscopy. NIR spectra were recorded from the films before tensile and bursting strength, and crystallinity tests. Spectral information were correlated with reference values obtained by laboratory procedures through partial least square regression (PLS-R). The PLS-R model for estimating the crystallinity index presented a coefficient of determination in cross-validation $\left(\mathrm{R}^{2} \mathrm{cv}\right)$ of 0,94 and the ratio of performance to deviation (RPD) was 3,77 . The mechanical properties of the films presented a high correlation with the NIR spectra: $R^{2} p=0,85(R P D=2,23)$ for tensile and $R^{2} p=0,93(R P D=3,40)$ for burst strength. The statistics associated to the models presented have shown that the NIR spectroscopy has the potential to estimate the crystallinity index and resistance properties of cellulose and nanocellulose films on in-line monitoring systems.
\end{abstract}

Keywords: Crystallinity index, mechanical properties, nanocellulose, NIRS, Pinus sp.

\section{INTRODUCTION}

The development of products from new technologies can create important breakthroughs in various sectors. Greater competitiveness and a more demanding market make the growth of the forest-base industry an even bigger challenge. Therefore, research for the innovation and improvement of products obtained from wood have been incentivized (Missoum et al. 2013).

Wood is a complex material shaped by nanometric structures that exhibit biometric properties, as well as by the architecture and the organization of these structures (Kollmann and Côté 1968, Déjardin et al. 2010). The most adequate and rational use of wood as a raw material can be reached through extensive knowledge of its properties, and the understanding that each property could present greater or less importance, depending on the intended final product (Walker 2006). Near Infrared (NIR) spectroscopy has been applied in the forestry field to evaluate the properties of wood (Tsuchikawa and Schwanninger 2013). The technique allows the analysis of organic compounds, including nanostructured films, since the spectral occurrences in this region derive mainly from the following

\footnotetext{
${ }^{1}$ Centro de Ciências Florestais e da Madeira, Departamento de Engenharia e Tecnologia Florestal, Universidade Federal do Paraná, Curitiba, Paraná, Brazil.

${ }^{2}$ Ciência e Tecnologia da Madeira, Departamento de Ciências Florestais, Universidade Federal de Lavras-Campus Universitário, Lavras, Minas Gerais, Brazil,

${ }^{3}$ EMBRAPA Florestas, Estrada da Ribeira, Colombo, Paraná, Brazil.

- Corresponding author: licvianna@gmail.com

Received: 11.08.2015 Accepted: 15.05.2016
} 
bonds: C-H, O-H, N-H, S-H and C=O (Pasquini 2003).

Associating chemometric tools and NIR spectroscopy makes possible quantitative and qualitative information concerning a range of materials (Burns and Ciurczak 2008). In the forestry sector, many studies have presented the analytical potential of NIR in discrimination of wood species (Nisgoski et al. 2015), in estimating chemical (Venãs and Rinnan 2008, Hein et al. 2010a, Esteves et al. 2013), physical (Rosso et al. 2013), mechanical (Kelley et al. 2004, Fujimoto et al. 2007), anatomic (Viana et al. 2009, Sánchez et al. 2013) and ultrastructural (Hein et al. 2010b) properties of wood and its products, as oriented strand boards (Kent et al. 2006), particle boards (Hein et al. 2011), medium density fibers boards (Rials et al. 2002, Belini et al. 2011) and cement-wood panels (Hein et al. 2009).

Regarding to cellulosic pulp, many studies have presented promising results for quantitative analysis of its properties through NIR (Fardim et al. 2002, Pereira et al. 2015, including the efficiency and Kappa number (Henriksen et al. 2005, Alves et al. 2007, Santos et al. 2014). The investigation of the potential of NIR spectroscopy in order to estimate the mechanical properties of paper is relatively limited, although some studies have presented promising findings (Fardim et al. 2005, Trafela et al. 2007, Samistraro and Muniz, 2009). To our knowledge, there is no study reporting the use of NIR spectroscopy and multivariate statistics in order to estimate the technological characteristics of nanocellulosic films. Therefore, the goal of this study was to apply the NIR spectroscopy for estimating the crystallinity index, tensile and burst strength in cellulosic and nanocellulosic films.

\section{MATERIALS AND METHODS}

\section{Cellulosic and nanocellulosic films}

Cellulosic films were produced from cellulose fibers and nanofibers of bleached and unbleached Pinus sp. Kraft pulp. The cellulose nanofibers were obtained through a mechanical process of defibrillation using the Super Masscolloider grinder (Model: MKCA6-2, Masuko Sangyo Co. Ltd., Saitama, Japan). The pulps were mechanically processed through the grinder. The mechanical treatments were based on the number of the passes of the pulps through the grinder. Six treatments were applied: 2, 5, 10, 20, 30 and 40 passes for the bleached and unbleached pulps, besides the nonmechanical treatments, totalling 14 treatments, as can be observed in Table 1.

Table 1. Treatments used for producing nanostructured cellulosic films.

\begin{tabular}{|c|c|c|c|}
\hline Treatments $^{\text {a }}$ & Kraft pulp & Kappa number & Number of passes \\
\hline L00 & & 51,7 & 0 \\
\hline L02 & & 51,7 & 2 \\
\hline L05 & & 51,7 & 5 \\
\hline L10 & Unbleached & 51,7 & 20 \\
\hline L20 & & 51,7 & 30 \\
\hline L30 & & 51,7 & 40 \\
\hline L40 & & 51,7 & 0 \\
\hline T00 & & 3,6 & 2 \\
\hline T02 & & 3,6 & 5 \\
\hline T05 & & 3,6 & 10 \\
\hline T10 & Bleached & 3,6 & 20 \\
\hline T20 & & 3,6 & 30 \\
\hline T30 & & 3,6 & 40 \\
\hline T40 & & 3,6 & \\
\hline
\end{tabular}

${ }^{\mathrm{a}} \mathrm{L}$ : unbleached treatments; T: bleached treatments; the numbers after the letters L and T represent the number of passes through the grinder. 
NIR spectra were recorded on the same samples using reflectance mode before the tests for determining the crystallinity index and the tensile and burst strengths. The samples were previously placed in an acclimatized room with temperature of $23 \pm 2{ }^{\circ} \mathrm{C}$ and relative humidity of $50 \pm 2 \%$ for the standardization of readings in the same temperature and humidity. After the NIR spectral aquisition, the films were acclimatized again in the same condition to determine the crystallinity index and mechanical properties: tensile resistance and burst resistance.

Five and four specimens were used per treatment for the regression models for the tensile and burst strength tests, totaling a sample set composed by 70 and 56 specimens, respectively. NIR spectra were recorded from 28 specimens ( 2 per treatment) for the crystallinity index calibration.

\section{Spectral acquisition}

NIR spectra were obtained through a Bruker-Tensor 37 spectrometer (Bruker, Ettlingen, Germany) based on the Fourier transform using OPUS software (version 6.5). The spectral acquisition was carried out in the diffuse reflection mode directly on the films from 10000 to $4000 \mathrm{~cm}^{-1}$ with of $2 \mathrm{~cm}^{-1}$ resolution. The diffuse reflection spectra were used in the multivariate regression analysis after the percentage transformation in $[\log 10(1 /$ reflectance $)]$ absorbance. Three NIR spectra were recorded for each specimen and each NIR spectrum was obtained through the average of 64 scans. A sintered gold standard was used as background.

\section{NIR calibration and validation}

Partial least square (PLS) regression was applied for developing the calibration of the predictive models using The Unscrambler ${ }^{\circledR}$ software (version 10.1). Due to the limited number of samples of each treatment, the PLS regressions to estimate the crystallinity index were validated by cross-validation while the models for tensile and burst strength were validated by independent validation.

The models were adjusted with a maximum of 12 latent variables (LV), where the number of LV selected for each model was the one that minimized the residual variance of the calibration and validation. The verification of anomalous samples was performed through the Student residual graphic, although none was excluded from the models. The NIR range presenting higher regression coefficients were selected for each model though the uncertainty test by Westad and Martens (2000). First derivatives (13-point filter and a second order polynomial) were applied on the NIR spectra data using Savitsky and Golay (1964) algorithm.

The statistics used for the selecting calibration and validation models were: coefficient of determination in cross-validation $\left(R^{2} c v\right)$ or independent test set $\left(R^{2} p\right)$, Root Mean Square Error of Cross-Validation (RMSECV) or independent test set (RMSEP), number of latent variables (LV) and the ratio of performance to deviation (RPD). The RMSE's measures the efficiency of calibration in predicting the properties in unknown samples (Schimleck et al. 2003) while the RPD corresponds to the ratio between the standard deviation of the reference values and the RMSE. This value allows comparing calibrations of different properties, once it enables the standardization of the estimated standard error (Williams and Sobering 1993, Williams 2014). 


\section{RESULTS AND DISCUSSION}

\section{NIR Spectra}

Figure 1 presents the NIR spectra of unbleached and bleached nanocellulosic films treated mechanically at different intensities. The intensity of absorbance variation according to the mechanical treatments to which the materials were submitted. Graphics b and c of Figure 1 present the spectra treated by the first derivative of unbleached and bleached materials, respectively.

The magnitude range (maximum and minimum) of the first derivative NIR spectra is higher in unbleached materials (Figure 1b) because these materials present a Kappa number of 51,7 and, therefore, are darker. The first derivative spectra of the unbleached (Figure 1b) and bleached (Figure 1c) materials present maximums and minimums in the same absorption bands, indicating the mechanical treatment does not cause alterations to the chemical structure of functional groups.

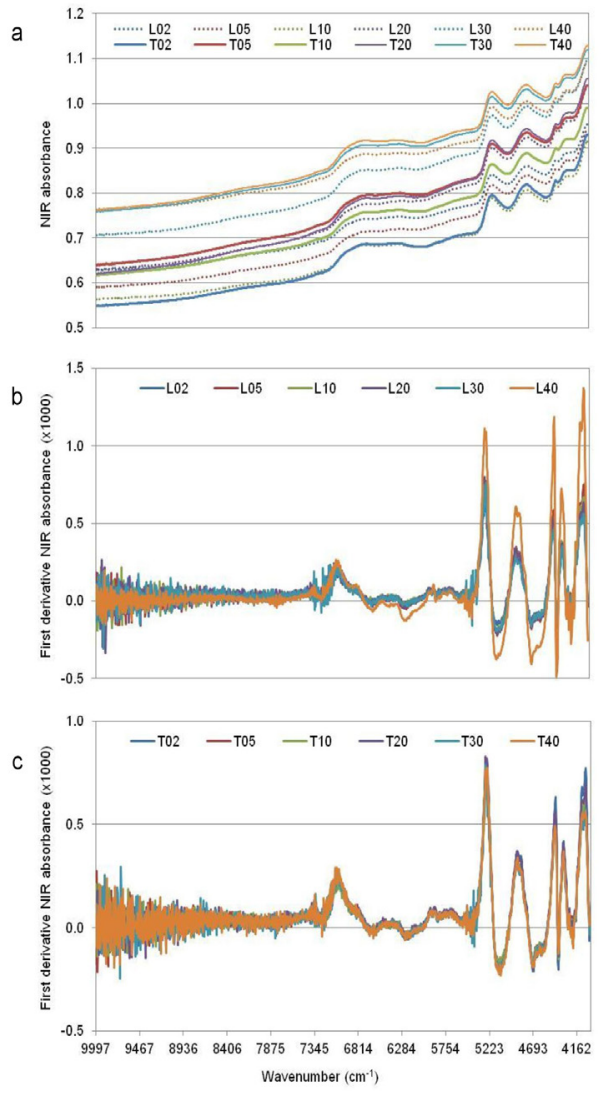

Figure 1. Original NIR Spectra of the materials submitted to mechanical treatments (a) and first NIR Spectra derivative of unbleached (b) and bleached (c) materials.

However, the graphics in Figure $1 \mathrm{~b}$ and $\mathrm{c}$ reveal a magnitude variation in the peaks as the material was refined mechanically. The peaks associated with the semi-crystalline and crystalline regions of the cellulose presented a reduction in the intensity associated with the decrease of crystallinity. Therefore, it is assumed that the process of defibrillation generates alterations at the molecular level due to the dissolution of carbohydrates or to the aggregation of cellulose nanofibers, as also suggested by Fardim et al.(2005) when evaluating pulps with different refining degrees. 


\section{NIR models to characterize materials}

Table 2 lists the summary of the statistics associated with the partial least square regression developed to estimate the crystallinity index, and tensile and burst strength properties from NIR spectra. The selected models were the ones which presented higher coefficients of determination and lower RMSE values for cross-validation and independent test set validation. The models were performed from the untreated spectra and from the first derivative (Savitzky and Golay 1964) NIR spectra.

Table 2. Independent and cross-validation of PLS models to estimate the tensile index (TI) and the index of burst (BI) of nanostructured cellulosic films from NIR spectra.

\begin{tabular}{|c|c|c|c|c|c|c|c|c|c|c|}
\hline Prop & Model & $\mathrm{N}^{\mathrm{a}}$ & $\mathrm{Trat}^{\mathrm{b}}$ & $\mathrm{LV}^{\mathrm{c}}$ & $\mathrm{R}^{2} \mathrm{cv}^{\mathrm{d}}$ & RMSECV $^{\mathrm{e}}$ & $\mathrm{RPD}^{\mathrm{f}}$ & $\mathrm{R}^{2} \mathrm{p}^{\mathrm{g}}$ & RMSEP $^{\mathrm{h}}$ & $\mathrm{RPD}$ \\
\hline \multirow{4}{*}{ TI } & 1 & 70 & - & 9 & 0,86 & 8,59 & 2,64 & 0,74 & 11,27 & 2,08 \\
\cline { 2 - 12 } & 2 & 70 & $1 \mathrm{~d}$ & 5 & 0,77 & 11,09 & 2,05 & 0,83 & 9,85 & 2,08 \\
\cline { 2 - 12 } & 3 & 60 & - & 3 & 0,57 & 11,25 & 1,50 & 0,65 & 11,32 & 1,19 \\
\cline { 2 - 11 } & 4 & 60 & $1 \mathrm{~d}$ & 3 & 0,73 & 8,82 & 1,91 & 0,85 & 6,56 & 2,23 \\
\hline \multirow{4}{*}{ BI } & 5 & 56 & - & 6 & 0,91 & 0,777 & 3,35 & 0,93 & 0,766 & 3,40 \\
\cline { 2 - 11 } & 6 & 56 & $1 \mathrm{~d}$ & 4 & 0,90 & 0,855 & 3,05 & 0,88 & 0,987 & 2,28 \\
\cline { 2 - 11 } & 7 & 48 & - & 6 & 0,84 & 0,813 & 2,50 & 0,81 & 0,904 & 2,06 \\
\cline { 2 - 11 } & 8 & 48 & $1 \mathrm{~d}$ & 3 & 0,86 & 0,779 & 2,61 & 0,87 & 0,774 & 2,67 \\
\hline
\end{tabular}

${ }^{a} \mathrm{~N}$ : number of samples; ${ }^{\mathrm{b}}$ Treat: mathematical treatment $1 \mathrm{~d}$ - first derivative; ${ }^{\mathrm{c}} \mathrm{LV}$ : number of latent variables; ${ }^{\mathrm{d}} \mathrm{R}^{2} \mathrm{c}:$ determination coefficient of calibration; ${ }^{\mathrm{e}} \mathrm{RMSEC}$ : standard error of calibration $(\mathrm{IC}=\%) ;{ }^{\mathrm{f}} \mathrm{R}^{2} \mathrm{cv}$ : determination coefficient of cross-validation; ${ }^{\mathrm{g}} \mathrm{RMSECV}$ : standard error of cross-validation (IC $\left.=\%\right) ;{ }^{\mathrm{h}} \mathrm{RPD}$ : ratio of performance to deviation.

The predictive models for tensile index were developed from 2 data sets: the set presented by 70 specimens includes NIR spectra recorded before mechanical treatment, while the data set presented by 60 specimens only contains the refined films. Regarding the models of the burst index, the calibrations adjusted with 56 samples include the non-treated materials and those from 48 samples contains only mechanically processed films.

Table 3 presents the statistics associated with the calibrations and cross-validations of NIR models to estimate the crystallinity index (CI) of nanostructured cellulosic films.

Table 3. Calibration and cross-validation of PLS models to estimate de crystallinity index (CI) of nanostructures cellulosic films from NIR spectra.

\begin{tabular}{|c|c|c|c|c|c|c|c|c|c|}
\hline Prop & Model & ${ }^{\mathrm{a}} \mathrm{N}$ & ${ }^{\mathrm{b}}$ Trat & ${ }^{\mathrm{c}} \mathrm{LV}$ & ${ }^{\mathrm{d}} \mathrm{R}^{2} \mathrm{c}$ & ${ }^{\mathrm{e}}$ RMSEC & ${ }^{\mathrm{fR}^{2} \mathrm{cv}}$ & ${ }^{\text {g}} \mathrm{RMSECV}$ & ${ }^{\mathrm{h}} \mathrm{RPD}$ \\
\hline \multirow{4}{*}{$\mathrm{CI}$} & 9 & 28 & - & 5 & 0,96 & 0,943 & 0,94 & 1,268 & 3,77 \\
\cline { 2 - 11 } & 10 & 28 & $1 \mathrm{~d}$ & 4 & 0,99 & 0,481 & 0,92 & 1,404 & 3,41 \\
\cline { 2 - 10 } & 11 & 24 & - & 5 & 0,92 & 0,880 & 0,87 & 1,276 & 2,53 \\
\cline { 2 - 10 } & 12 & 24 & $1 \mathrm{~d}$ & 3 & 0,95 & 0,709 & 0,83 & 1,484 & 2,18 \\
\hline
\end{tabular}

${ }^{\mathrm{a}} \mathrm{N}$ : number of samples; ${ }^{\mathrm{b}}$ Treat: mathematical treatment $1 \mathrm{~d}$ - first derivative; ${ }^{\mathrm{c}} \mathrm{LV}$ : number of latent variables; ${ }^{\mathrm{d}} \mathrm{R}^{2} \mathrm{c}:$ determination coefficient of calibration; ${ }^{\mathrm{e}} \mathrm{RMSEC}$ : standard error of calibration $(\mathrm{IC}=\%) ;{ }^{\mathrm{f}} \mathrm{R}^{2} \mathrm{cv}$ : determination coefficient of cross-validation; ${ }^{\mathrm{g}} \mathrm{RMSECV}$ : standard error of cross-validation ( $\left.\mathrm{IC}=\%\right) ;{ }^{\mathrm{h}} \mathrm{RPD}$ : ratio of performance to deviation.

As the number of samples was relatively higher, it was possible to validate the calibrations to 
estimate TI and BI using two different approaches: independent test set and cross-validation (Table 2). For CI, only the cross-validation was used due to limitations in samples number (Table 3 ).

The independent and/or cross-validations presented promising statistics for fast characterization of films. In short, the models that included all samples (before and after the treatment) presented $\mathrm{R}^{2} \mathrm{p}$ and RMSEP similar to when the spectra were treated by the first derivative. Generally, the use of spectral treatment (first derivative) resulted in the decrease of the number of latent variables required by the NIR model.

\section{NIR calibration for tensile index}

The tensile index of nanostructured cellulosic films also could be estimated by multivariate models based on NIR spectra. The predictive models for TI (models 1 to 4, Table 2) were validated by sub-lots that belonged to the calibration set (cross-validation) and by an independent set. The $\mathrm{R}^{2}$ of the independent test set and cross-validation models varied between 0,65 and 0,83 depending of the spectral treatment (raw or first derivative) or the collection of used samples (Table 2). In general, the first derivative treatment improved the informative capacity of the NIR spectrum in comparison to the tensile index of cellulosic films.

Figure 2 presents the comparison between the values determined in the laboratory and the values estimated by model 4 , the regression that generated estimates closer to the reference values.

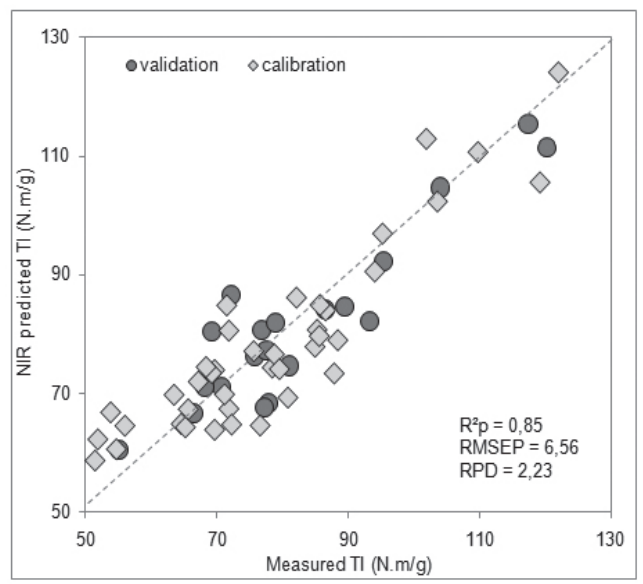

Figure 2. Relation between the tensile index (TI) values determined by traditional mechanic trial and estimated by NIR Spectroscopy.

The models 2 and 4 to estimate the tensile index of films from the first derivative NIR spectra presented better adjustments $\left(R^{2} p>80\right)$. From these statistics, it can be suggested that the regressions presented little sensibility in comparison to the presence or not of non-treated samples. Figure 2 reveals that there was no cluster formation and the RMSEP of model 4 was the lowest $(6,56 \mathrm{~N} . \mathrm{m} / \mathrm{g})$.

\section{NIR Calibration for burst strength index}

The calibrations to estimate the burst index of films presented satisfying statistics. The $\mathrm{R}^{2}$ of these validations vary from 0,71 to 0,93 and the RMSE did not exceed $1 \mathrm{KPa} \cdot \mathrm{m}^{2} / \mathrm{g}$ (Table 2). Model 5 was generated from the untreated NIR spectra and includes samples not processed mechanically. This model presented the highest $\mathrm{R}^{2}$ and RPD and the lowest RMSE. The relation between the burst index values determined through the universal testing machine and the values estimated through model 5 are 
presented in Figure 3.

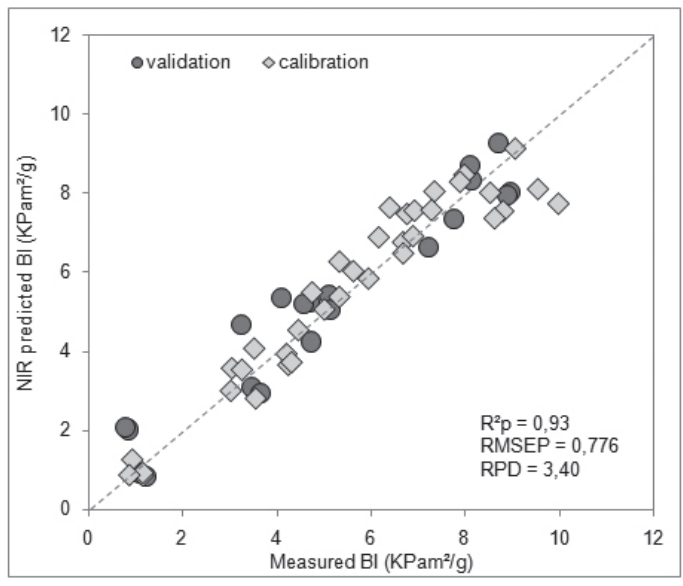

Figure 3. Relation between the burst index (BI) values determined by traditional mechanical trail and estimated by NIR Spectroscopy.

Samistraro and Muniz (2009) reported NIR based calibrations to estimate the properties of Kraft paper with $\mathrm{R}^{2}$ in calibrations of 0,88 for burst and of 0,86 for transversal tensile using nine and six latent variables, respectively.

\section{NIR Calibration for the crystallinity index}

The calibrations to estimate the CI (models 9 to 12 , Table 3 ) presented $\mathrm{R}^{2} \mathrm{cv}$ varying between 0,83 and 0,94 and RPD of 2,18 to 3,77 . The models with the most adequate statistics were generated using the untreated NIR spectra (models 9 and 11), which, despite requiring more latent variables to fit, presented higher $\mathrm{R}^{2}$ and lower RMSE. Figure 4 presents the dispersion of the crystallinity index (CI) values determined in the laboratory and estimated through NIR from model 9. To estimate the crystallinity index, model 9 required the use of 5 latent variables; spectral treatment was not used and was originated from the information of 28 samples.

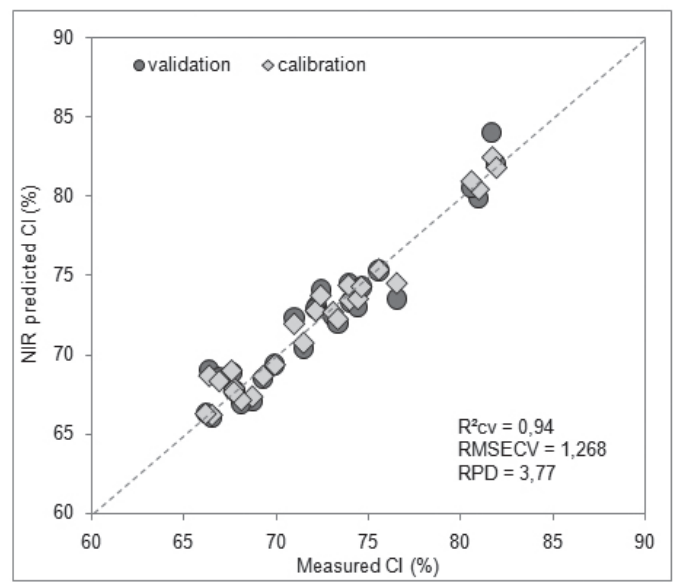

Figure 4. Relation between the crystallinity index (CI) values determined by traditional mechanical trials and estimated through NIR Spectroscopy. 
The crystallinity index of cellulose in films could be estimated through a calibration (model 9) for which cross-validation presented a $\mathrm{R}^{2} \mathrm{p}$ of 0,94 an average square root of the lower deviation of $1,3 \%$ and a RPD of 3,77 (Figure 4). It is possible to observe that the eight samples meant for the nonmechanical treatment evaluation were part of the modeling. When these samples were withdrawn from the calibration set (models 11 and 12), the statistics suffered a reduction, although it still provides good estimates $\left(\mathrm{R}^{2} \mathrm{cv}>0,80\right.$ and $\left.\mathrm{RMSECV}<1,5 \%\right)$.

\section{Regression coefficients}

The graphic analysis of the regression coefficients is useful to understand the underlying relations between the magnitude of reflex in certain spectral regions and the variation in the properties of the analyzed material. It is through interactions between these absorbance bands and the technological characteristics of the cellulosic films that it is possible to analyze the tensile, burst and crystallinity indices through the NIR spectra.

Contribution of the absorbance bands to the NIR calibration are presented in Figure 5 for the burst index (black line) and crystallinity (grey line) and in Figure 6 for the tensile index, which was adjusted from the first derivative NIR spectra.

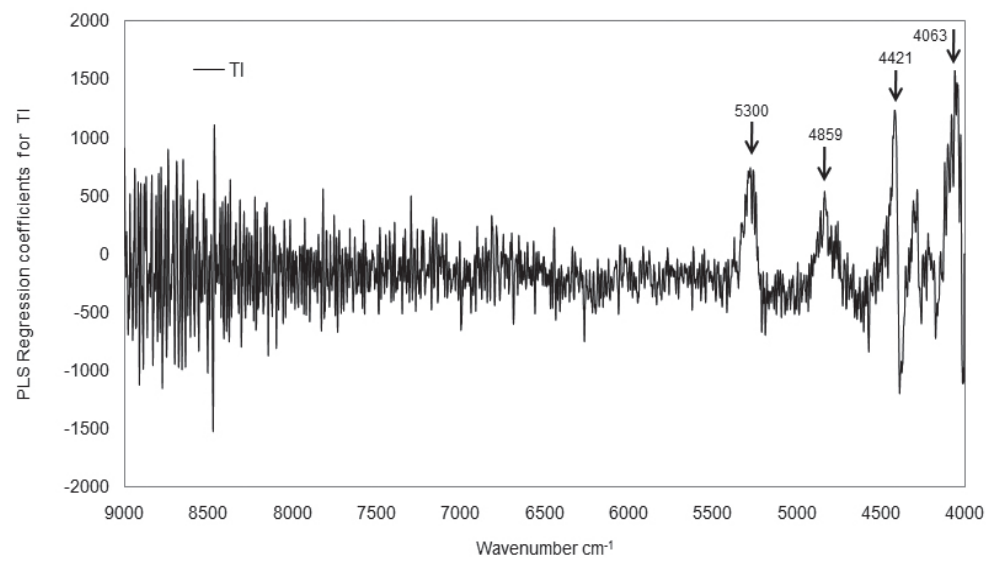

Figure 5. Regression coefficients to estimate the tensile index from NIR spectra.

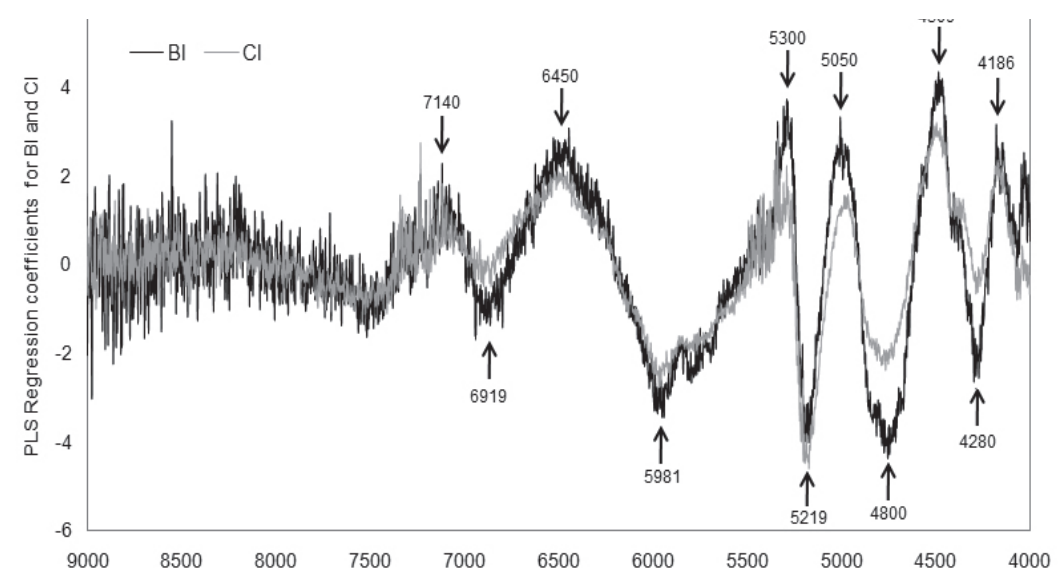

Figure 6. Regression coefficients to estimate the burst and crystallinity indices from the NIR spectra. 
The coefficients' magnitudes in the regressions are useful to identify functional groups that were important for the models presented in Figures 2, 3 and 4. Figures 5 and 6 give a better understanding of how NIR Spectroscopy can be applied to evaluate physical, mechanical and chemical characteristics of nanostructured films.

In Figures 5 and 6, the absorbance bands were indicated by arrows, as well as their respective wavelength values $\left(\mathrm{cm}^{-1}\right)$ that influenced most in the construction of the models. Between the highlighted bands, some did not present defined attributions $\left(5300,4509,4186 \mathrm{~cm}^{-1}\right)$. The coefficient regressions shown in Figures 5 and 6 appear to present noise probably due to the low resolution $\left(2 \mathrm{~cm}^{-1}\right)$ used for recording NIR spectra.

The region near the absorbance band at $7140 \mathrm{~cm}^{-1}$ was associated to the amorphous structure of cellulose. Tsuchikawa and Siesler (2003a and b) have used NIR spectroscopy to identify and separate the amorphous, semi-crystalline and crystalline regions of the pulp from conifers and hardwoods between the wavelength range of 7200-6100 $\mathrm{cm}^{-1}$. According to the authors, the region $\left(7200-6100 \mathrm{~cm}^{-}\right.$ $\left.{ }^{1}\right)$ could be assigned to the first overtone of stretching vibration of the $\mathrm{OH}$ group. The wavelengths of 7000 to $6900 \mathrm{~cm}^{-1}$ were associated to the absorption, in $\mathrm{OH}$ groups, of amorphous regions of cellulose, due to the great accessibility noticed in the region. The region between $6800-6600 \mathrm{~cm}^{-1}$ was classified as semi-crystalline due to the accessibility of $\mathrm{OH}$ groups, which showed an intermediate value between amorphous and crystalline regions; and, at last, the crystalline regions were associated to the range between 6500 and $6300 \mathrm{~cm}^{-1}$. Knowing the band's characteristics of the $\mathrm{OH}$ group at $6775 \mathrm{~cm}^{-1}$ it could be assigned to the semi crystalline region of cellulose, and at $6450 \mathrm{~cm}^{-1}$, relative to the stretching of the $\mathrm{OH}$ group, it is assigned to the crystalline regions of the cellulose (Tsuchikawa and Siesler 2003a, Fujimoto et al. 2007).

The peak of $5981 \mathrm{~cm}^{-1}$ corresponds to the first overtone stretch of the $\mathrm{CH}$ aromatic groups assigned to the lignin. At 5219 and $5050 \mathrm{~cm}^{-1}$, it is due to the combination of vibrational stretch and deformation of the $\mathrm{OH}$ group in water (Mitsui et al. 2007, Fujimoto et al. 2008).

For the bands between $4890-4620 \mathrm{~cm}^{-1}$, the peak at $4280 \mathrm{~cm}^{-1}$ could be assigned to the semi or crystalline regions of cellulose, and at $4421 \mathrm{~cm}^{-1}$, to the hemicelluloses (Osborne and Fearn 1986). The band of 4392-4365 $\mathrm{cm}^{-1}$ was assigned to the cellulose, with the peak at $4063 \mathrm{~cm}^{-1}$ (Workman and Weyer 2007, Huang et al. 2012).

Through the analysis of the regression coefficients, it is noticeable that the bands that contributed the most for the generation of calibration models of the crystallinity index were mainly related to the cellulose structure, once the crystallinity index refers to the quantity of cellulose in the crystalline region (ordered), the region of the fiber where there is higher tensile strength to stretching and salvation (Fengel and Wegener 1984).

The content of cellulose and crystallinity were also important in the calibration models for tensile and burst index in films, as stated in other studies. Fujimoto et al. (2007), using NIR for the prediction of mechanical properties of wood, concluded that the absorbance band related to the $\mathrm{OH}$ groups in crystalline and semicrystalline regions strongly influenced in the calibrations to determine the mechanical properties, and indicated a positive correlation between $\alpha$-cellulose, the crystalline region and the resistance of wood. For nanostructured films, authors stated a decrease of tensile and burst in films, along with a reduction in the crystallinity index, observed with the increase of passes (Iwamoto et al. 2008).

Tensile and burst properties in papers do not depend on just one factor, they should rather be interpreted along with a set of factors related to raw material characteristics and the cellulose extraction process, such as inter-fibers bonds, fiber length, beating degree, bleaching time, density of paper and also crystallinity index (Stelte and Sanadi 2009, Okan et al. 2015).

Interactions between atoms of different molecules change the states of vibration energies, dislocating absorption bands that already existed and creating new ones, reflecting differences in the crystalline structure. Thus, different crystalline structures could be distinguished and physical properties such as density, viscosity could also be determined in an indirect way. It could be said that the NIR spectra 
also contains, besides chemical information, physical information that could be used to determine such properties of the samples (Blanco and Villarroya 2002).

\section{CONCLUSIONS}

The results presented in this study show that NIR Spectroscopy and least square regression present the potential to predict the crystallinity index, and tensile and burst properties of nanocellulosic and cellulosic films. The calibrations presented PLS models with statistics considered satisfactory, where the regression coefficient values in the validation vary from 0,85 to 0,94 and the ratio performance to deviation (RPD) varied from 2,23 to 3,77 . The model to predict the crystallinity index of cellulose presented higher performance. Through the analysis of the regression coefficients, it is probable to claim that the cellulose, mainly in the crystalline and semi-crystalline regions, is strongly influenced in the calibrations to predict tensile and burst properties of the films. The NIR technique could be a viable tool for the fast determination of tensile properties of cellulosic and nanocellulosic films in online monitoring systems.

\section{ACKNOWLEDGMENTS}

The authors are thankful to the Fundação Araucária and Coordenação de Aperfeiçoamento de Pessoal de Nível Superior - CAPES for the financial support.

\section{REFERENCES}

Alves, A.; Santos, A.; Perez, D.S.; Rodrigues, J.; Pereira, H.; Simões, R.; Schwanninger, M. 2007. NIR PLSR model selection for Kappa number prediction of maritime pine Kraft pulps. Wood Sci Technol 41:491-499.

Belini, U.L.; Hein, P.R.G.; Tomazello, M.F.O.; Rodrigues, J.C.; Chaix, G. 2011. Near infrared spectroscopy for estimating sugarcane bagasse content in medium density fiberboard. BioResources 6:1816-1829.

Blanco, M.; Villarroya, I. 2002. NIR spectroscopy: a rapid-response analytical tool. Trends anal. Chem 21:240-250.

Burns, D.A.; Ciurczak, E.W. 2008. Handbook of near-infrared analysis. 3. ${ }^{\text {ed } . ~ C R C, ~ B o c a ~ R a t o n . ~}$

Déjardin, A.; Laurans, F.; Arnaud, D.; Breton, C.; Pilate, G.; Leple, J.C. 2010. Wood formation in Angiosperms. C. R. Biologies 333:325-334.

Esteves, B.; Marques, A.V.; Domingos, I.; Pereira, H. 2013. Chemical changes of heat treated Pine and Eucalypt wood monitored by FTIR. Maderas. Ciencia y tecnología 15(2): 245-258.

Fardim, P.; Ferreira, M.M.C.; Durán, N. 2002. Multivariate calibration for quantitative analysis of Eucalyptus Kraft pulp by NIR spectrometry. J Wood Chem Technol 22:67-81

Fardim, P.; Ferreira, M.M.C.; Durán, N. 2005. Determination of Mechanical and Optical Properties of Eucalyptus Kraft Pulp by NIR Spectrometry and Multivariate Calibration. J Wood Chem Technol 25:267-279.

Fengel, D.; Wegener, G. 1984. Wood chemistry, ultrastructure, reactions. Walter de Gruyter, New York. 
Fujimoto, T.; Kurata, Y.; Matsumoto, K.; Tsuchikawa, S. 2008. Application of near infrared spectroscopy for estimating wood mechanical properties of small clear and full length lumber specimens. J Near Infrared Spectrosc 16:529-537.

Fujimoto, T.; Yamamoto, H.; Tsuchikawa, S. 2007. Estimation of Wood Stiffness and Strength Properties of Hybrid Larch by Near-Infrared Spectroscopy. Appl Spectrosc 61:882-888.

Hein, P.R.G.; Campos, A.C.M.; Mendes, R.F.; Mendes, L.M.; Chaix, G. 2011. Evaluation of bio-based particleboards properties by near infrared spectroscopy. Eur J Wood Prod 69:431-442.

Hein, P.R.G.; Clair, B.; Brancheriau, L.; Chaix, G. 2010b. Predicting microfibril angle in Eucalyptus wood from different wood faces and surface qualities using near infrared spectra. $J$ Near Infrared Spectrosc 18:455-464.

Hein, P.R.G.; Lima, J.T.; Chaix, G. 2010a. Effects of sample preparation on NIR spectroscopic estimation of chemical properties of Eucalyptus urophylla S.T. Blake wood. Holzforschung 64:45-54.

Hein, P.R.G.; Sá, V.A.; Bufalino, L.; Mendes, L.M. 2009. Calibrations based on near infrared spectroscopic data to estimate wood-cement panel properties. BioResources 4:1620-1634.

Henriksen, H.C.; Naes, T.; Rodbotten, R.; Aastveit, A. 2005. Simultaneous modelling of process variables and raw material properties as measured by NIR. A case study from cellulose production. Chemometr Intell Lab Systems 77:238-246.

Huang, J.; Xia, T.; Li A, Y.U.B.; Qing, L.; Tu, Y.; Zhang, W.; YI, Z.; Peng, L. 2012. A rapid and consistent near infrared spectroscopic assay for biomass enzymatic digestibility upon various physical and chemical pretreatments in Miscanthus. Bioresource Technology 121:274-281.

Iwamoto, S.; Kentaro, A.; Yano, H. 2008. The effect of hemicelluloses on wood pulp nanofibrillation and nanofiber network characteristics. Biomacromolecules 9:1022-1026.

Kelley, S.S.; Rials, T.G.; Snell, R.; Groom, L.H.; Sluiter, A. 2004. Use of near infrared spectroscopy to measure the chemical and mechanical properties of solid wood. Wood Sci Technol $38: 257-276$.

Kent, S.M.; Leichti, R.J.; Morrell, J.J.; Rosowsky, D.V.; Kelley, S.S. 2006. Analytical tools to predict changes in properties of oriented strandboard exposed to the fungus Postia placenta. Holzforschung 60:332-338.

Kollmann, F.F.P.; Coté, W.A. 1968. Principles of Wood science and technology. Springer-Verlag, New York.

Missoum, K.; Belgacem, M.N.; Bras, B. 2013. Nanofibrillated Cellulose Surface Modification: A Review. Materials 6:1745-1766.

Mitsui, K.; Inagaki, T.; Tsuchikawa, S. 2007. Near infrared spectroscopy assay for thermal treatment of wood. in: European conference on wood modification, Cardiff. Proceedings. Gwynedd: B.C. 3:335-343.

Nisgoski, S.; Carneiro, M.E.; Muñiz, G.I.B. 2015. Influencia de la granulometria de la muestra en la discriminación de especies de Salix por infrarrojo cercano influence of sample granulometry on discrimination of Salix species by near infrared. Maderas.Ciencia y tecnología 17(1):195-204.

Okan, O.T.; Deniz, I.; Tiryaki, S. 2015. Application of artificial neural networks for predicting tensile index and brightness in bleaching pulp. Maderas.Ciencia y tecnología 17(3):571-584.

Osborne, B.G; Fearn, T. 1986. Near Infrared Spectroscopy in Food Analysis. Longman Scientific and Technical, Harlow.

Pasquini, C. 2003. Near infrared spectroscopy: fundamentals, practical aspects and analytical applications. J Braz Chem Soc 14:198-219.

Pereira, H.; Santos, A.J.A.; Anjos, O. 2015. Fibre Morphological Characteristics of Kraft Pulps of Acacia melanoxylon Estimated by NIR-PLS-R Models. Materials 9(1):1-9. 
Rials, T.G.; Kelley, S.S.; So, C.L. 2002. Use of advanced spectroscopic techniques for predicting the mechanical properties of wood composites. Wood Fiber Sci 34:398-407.

Rosso, S.; Muniz, G.I.B.; Matos , J.L.M.; Haselein, C.R.; Hein, P.R.G.; Lopes, M.C. 2013. Estimate of the density of Eucalyptus grandis W. Hill ex Maiden using near infrared spectroscopy. Cerne 19:647-652.

Samistraro, G.; Muniz, G.I.B. 2009. Previsão das propriedades físicas do papel Kraft por espectroscopia no infravermelho próximo (NIR) e regressão por mínimos quadrados parciais (PLS). Quím Nova 32:1422-1425.

Sánchez, I.G.; Ceca, J.L.G.; Olmo, J.G.; Buil, L.L.; Luque, R.L.; Prades,C. 2013. Aplicación de analisis de imagen y tecnología nirs a la evaluacion de la porosidad de planchas, láminas y tapones decorcho y su relacion con la calidad industrial. Maderas. Ciencia y tecnología 15(3):293-309.

Santos, A.J.A.; Anjos, O.; Simões, R.; Rodrigues, J.; Pereira, H. 2014. Kappa Number Prediction of Acacia melanoxylon Unbleached Kraft Pulps using NIR-PLSR Models with a Narrow interval of Variation. BioResources 9(4):6735-6744.

Savitzky, A.; Golay, M.J.E. 1964. Smoothing and differentiation of data by simplified leastsquares procedures. Anal Chem 36:1627-1639.

Schimleck, L.R.; Doran, J.C.; Rimbawanto, A. 2003. Near infrared spectroscopy for costeffective screening of foliar oil characteristics in a Melaleuca cajuputi breeding population. $J$ Agric Food Chem 51:2433-2437.

Stelte, W.; Sanadi, A.R. 2009. Preparation and Characterization of Cellulose Nanofibers from Two Commercial Hardwood and Softwood Pulps. Ind Eng Chem Res 48:11211-11219.

Trafela, T.; Strlic, M.; Kolar, J.; Lichtblau, D.A.; Anders, M.; Mencigar, D.P.; Pihlar, B. 2007. Nondestructive Analysis and Dating of Historical Paper Based on IR Spectroscopy and Chemometric Data Evaluation. Anal Chem 79:6319-6323.

Tsuchikawa, S.; Schwanninger, M. 2013. A Review of Recent Near Infrared Research for Wood and Paper (Part 2). Appl. Spectrosc Rev 48:560-587.

Tsuchikawa, S.; Siesler, H.W. 2003a. Near-infrared spectroscopy monitoring of the diffusion process of deuterium-labeled molecules in wood. Part II: hardwood. Appl Spectrosc 57:675-681.

Tsuchikawa, S.; Siesler, H.W. 2003b. Near-infrared spectroscopy monitoring of the diffusion process of deuterium-labeled molecules in wood. Part I: softwood. Appl Spectrosc 57:667-674.

Venãs, T.M.; Rinnan, A. 2008. Determination of weight percent gain in solid wood modified with in situ cured furfuryl alcohol by near-infrared reflectance spectroscopy. Chemometr Intell Lab Systems 92:125-130

Viana, L.C.; Trugilho, P.F.; Hein, P.R.G.; Lima, J.T.; Silva, J.R.M. 2009. Predicting morphological characteristics and basic density of Eucalyptus wood using the NIRS technique. Cerne $15: 421-429$.

Walker, J.C.F. 2006. Primary Wood Processing: Principles and Practice. 2. ${ }^{\text {ed }}$. Springer, New Zealand.

Westad, F.; Martens, H. 2000. Variable selection in near infrared spectroscopy based on significance testing in partial least square regression. J Near Infrared Spectrosc 8:117-124.

Williams, P.C. 2014. Tutorial: The RPD statistic: a tutorial note. NIR News 25: 22-26. doi: 10.1255/ nirn.1419.

Williams, P.C.; Sobering, D.C. 1993. Comparison of commercial near infrared transmittance and reflectance instruments for analysis of whole grains and seeds. J Near Infrared Spectrosc 1:25-33.

Workman, J.J.; Weyer, L. 2007. Practical Guide to Interpretive Near-Infrared Spectroscopy. CRC Press, Boca Raton. 